MaPan : Jurnal Matematika dan Pembelajaran

p-ISSN: 2354-6883 ; e-ISSN: 2581-172X

Volume 7 No 1, June 2019 (74-84)

DOI: https://doi.org/10.24252/mapan.2019v7n1a6

\title{
MENGIDENTIFIKASI SIFAT-SIFAT BANGUN DATAR MELALUI "BERMAIN POLA" DAN EFEKTIVITASNYA TERHADAP KEMAMPUAN SPASIAL SISWA SEKOLAH DASAR
}

\author{
Valeria Suryani Kurnila1), Yohanes Kurniawan'2), Apolonia Hendrice Ramda3) \\ 1,2,3STKIP Santu Paulus \\ 1,2,3Jl. Jendral Ahmad Yani No. 10, Ruteng, Flores, NTT \\ E-mail: valeria.suryani@gmail.com ${ }^{1)}$, yohaneskurniawan91@gmail.com ${ }^{2)}$, \\ apoloniahendrice@gmail.com ${ }^{3}$
}

Submitted: 27-09-2018, Revised: 02-06-2019, Accepted: 27-06-2019

\begin{abstract}
Abstrak:
Penelitian ini bertujuan mengembangkan permainan "Bermain Pola" yang layak, dan mengetahui efektivitas permainan tersebut dalam meningkatkan kemampuan spasial. Permainan "Bermain pola" ini dikembangkan untuk melatih siswa sekolah dasar mengidentifikasi sifat-sifat bangun datar. Metode penelitian yang digunakan adalah penelitian dan pengembangan. Permainan yang dikembangkan harus layak ditinjau dari aspek pendefinisian, perancangan, bahasa, kesesuaian dengan indikator pembelajaran serta pemilihan gambar yang tepat. Uji coba terbatas dan luas dilakukan di SDK (Sekolah Dasar Katolik) Kumba 1 dilengkapi dengan aturan permainannya serta perangkat pembelajaran berupa RPP, LKS, tes kemampuan spasial, lembar observasi aktivitas siswa, lembar pengamatan kemampuan guru dalam mengelola pembelajaran, dan angket respons siswa terhadap permainan tersebut. Sedangkan media bantu pembelajaran yang diperlukan adalah pola-pola bangun datar, stopwatch dan peluit. Data kemampuan spasial pada penelitian ini dikumpulkan menggunakan tes uraian. Efektivitas permainan terhadap kemampuan spasial diuji dengan menggunakan one sample t-test, dengan menggunakan kriteria ketuntasan minimal sebesar 65. Hasil penelitian ini menghasilkan permainan "Bermain Pola" serta penggunaannya yang efektif terhadap kemampuan spasial siswa Sekolah Dasar.
\end{abstract}

Kata Kunci: Bangun Datar, Bermain Pola, Kemampuan Spasial

\section{INDENTIFYING THE CHARACTERISTIC OF TWO-DIMENSIONAL FIGURE THROUGH PLAYING "PATTERNS" AND ITS EFECTIVENESS TOWARDS ELEMENTARY SCHOOL STUDENTS' SPATIAL ABILITY}

\begin{abstract}
:
This study aimed to developing a decent "Playing Pattern" game, and knowing the effectiveness of the game in improving spatial abilities. This "Play pattern" game was developed to train elementary school students to identify 2-dimensional build properties. The research method used was Research and Development ( $R \& D)$. The game developed must be feasible in terms of defining aspects, design, language, conformity with learning indicators and the selection of appropriate images. Limited and extensive trials conducted at SDK (Catholic Primary School) Kumba 1 with the rules of the game as
\end{abstract}


well as learning tools in the form of RPP, LKS, spatial ability tests, observation sheets of student activities, observation sheet teacher's ability to manage learning, and student response questionnaires to the game. Whereas the needed learning aid media were flat, stopwatch and whistle wake patterns. Data on spatial ability in this study were collected using description tests. The effectiveness of the game on spatial ability was tested using one sample t-test, using minimum completeness criteria of 65. The results of this study slowed that in the game "Playing Pattern" and its effective use of spatial abilities of elementary school students.

Keywords: 2-Dimensions Figure, Play Patterns, Spatial Abilities

How to Cite: Kurnila, V. S., Kurniawan, Y., \& Ramda, A. H. (2019). Mengidentifikasi sifat-sifat bangun datar melalui "bermain pola" dan efektivitasnya terhadap kemampuan spasial siswa Sekolah Dasar. MaPan: Jurnal Matematika dan Pembelajaran, 7(1), 74-84.

\section{PENDAHULUAN}

Kelas matematika adalah sebuah komunitas yang melakukan aktivitas matematika, refleksi aktivitas matematika dan debat mengenai aktivitas matematika yang memunculkan aktivitas berpikir (Suwarma, 2009). Aktivitas tersebut dalam matematika tidak terlepas dari komunikasi. Komunikasi tidak hanya bersifat verbal, namun penggunaan simbol serta pengembangan visualisasi ruang menjadi bagian yang tidak terpisahkan dari komunikasi.

Geometri adalah salah satu cabang ilmu dalam matematika yang mempelajari berbagai hal terkait pengembangan visualisasi ruang. Ilmu tersebut dapat dipelajari dengan baik jika siswa memiliki kemampuan spasial. Kemampuan spasial merupakan kemampuan menyatakan kedudukan antar unsur-unsur suatu bangun ruang, mengidentifikasi gambar-gambar geometri, mengklasifikasi gambar-gambar geometri serta membayangkan bentuk atau posisi suatu objek geometri yang dipandang dari sudut pandang tertentu (Wahyudin, 2015). Tosto dalam penelitiannya menyatakan bahwa kemampuan spasial sangat penting dan merupakan predikat atau merupakan kunci keberhasilan dalam belajar matematika dan science (Tosto et al., 2014). Kemampuan spasial seseorang bergantung pada situasi atau keadaan lingkungan tempat tinggalnya (Bayram, 2009). Semakin banyak hal-hal pendukung terbentuknya kemampuan spasial di lingkungan sekitar seseorang, maka kemampuan spasialnya semakin baik. Oleh karena itu, proses pengenalan bangun datar serta pengidentifikasian sifat-sifatnya dapat dilakukan oleh guru dalam proses pembelajaran. Guru bisa memunculkan situasi atau kondisi yang 
mampu meningkatkan kemampuan spasialnya (Nugroho Prasetya \& Yohanes, 2018) .

Akan tetapi pada kenyataannya, kemampuan spasial yang diinginkan, tidak mudah dicapai karena berbagai macam persoalan yang dihadapi siswa SD. Hasil observasi dan wawancara terhadap 20 siswa SD Kumba 1 di kabupaten Manggarai, menunjukkan bahwa kemampuan spasial yang dimiliki siswa SD masih rendah. Siswa masih mengalami kesulitan ketika menyelesaikan soal-soal geometri, terutama pada soal-soal HOTS yang berkaitan dengan bangun datar. Dari hasil analisis menunjukkan bahwa siswa masih belum tepat mengidentifikasi sifat-sifat bangun datar, sehingga terjadi kesalahan dalam mengasosiasikan cerita pada soal dengan konsep sifat bangun datar yang dimilikinya.

Pengenalan bangun datar harus dilakukan secara terstruktur. Pengenalan tersebut bisa diawali dengan menampilkan sebuah model berbentuk persegi. Pengukuran panjang sisi pada model bangun datar tersebut dengan menggunakan satuan tidak baku, misalnya menggunakan sebatang kayu.

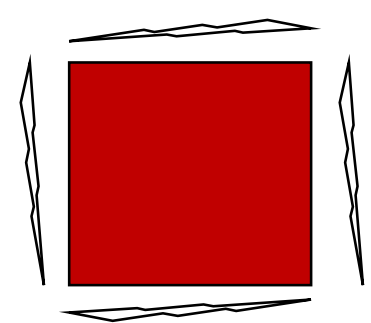

Gambar 1. Pengukuran Model Bangun Datar dengan Satuan Tidak Baku

Langkah selanjutnya, siswa melipat keempat sisi persegi tersebut secara vertikal dan horisontal. Hasil lipatannya berimpit pada kedua ujungnya dan membentuk dua bagian bangun datar persegi panjang yang memiliki panjang dan lebar yang sama.
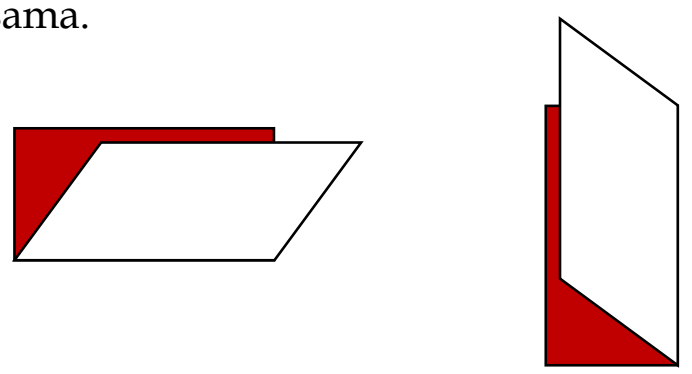

Gambar 2. Melipat Model Bangun Datar Secara Vertikal dan Horisontal 
Proses melipat merupakan salah satu cara untuk mengetahui besar sudut pada model bangun datar persegi. Selain melipat secara vertikal dan horisontal, dapat juga dilakukan proses melipat sesuai dengan garis diagonal pada bidang datar tersebut. Hasil lipatannya menunjukkan bahwa besar keempat sudutnya sama dan besarnya 90. Hasil lipatan mengikuti garis diagonal juga menunjukkan bahwa kedua garis diagonal tegak lurus.

Belajar mengidentifikasi bangun datar tidak hanya terbatas pada pengenalan bangun datar secara terpisah, namun siswa juga dituntut untuk mengenal perbedaan bangun datar yang satu dengan bangun datar lainnya. Kegiatan tersebut tentunya didukung oleh kelayakan buku teks pelajaran yang digunakan dalam proses pembelajaran. Hal ini penting karena buku teks adalah sumber belajar penunjang pembelajaran yang merupakan implementasi dari kurikulum (Ramda, Kurnila, \& Jundu, 2018). Agar penggunaan buku teks dalam pembelajaran bisa berjalan dengan baik, maka salah satu cara adalah dengan melibatkan siswa secara aktif dalam proses pembelajaran.

Proses pembelajaran seperti ini ternyata diterapkan juga di Tiongkok. Kurikulum di negara tersebut berorientasi pada pembelajaran yang mendorong siswa untuk berdiskusi, berpikir inovatif dan mengedepankan kualitas (Dickyandi, 2016). Siswa di Tiongkok diajarkan dan diarahkan untuk memahami, mengalami sesuatu yang dipelajari. Selain itu, murid-murid juga bisa menginternalisasikan pemahaman yang telah diperoleh (Dickyandi, 2016). Kurniawan dan kawan-kawan (Kurniawan, Jelatu, Adi, \& Kurnila, 2018) yang melakukan penelitian dengan menggunakan android dalam pembelajaran, menemukan bahwa pembelajaran menarik dan update mampu menggerakkan siswa dalam suasana pembelajaran yang aktif dan kreatif.

Hasil penelitian yang dilakukan Murat Peker (Peker, 2008) menyimpulkan bahwa guru harus mengetahui gaya belajar siswa dan mengakomodir hal tersebut dalam proses pembelajaran yang menyenangkan. Salah satu metode pembelajaran yang sejalan dengan hal tersebut adalah permainan. (Seifert \& Hoffnung, 1987), menjelaskan bahwa permainan memberikan kesempatan pada anak untuk menguasai masalah dengan mengatur objek dan situasi sosial, yang membiarkan anak tersebut berimajinasi serta mengontrol hasil imajinasinya sehingga mencapai kepuasan atau keinginan. (Derek, 2007) juga menambahkan bahwa dalam proses permainan perlu dilibatkan beberapa alat bantu atau benda-benda konkret.

Permainan dalam pembelajaran sebaiknya tidak dilakukan secara bebas. Guru harus memperhatikan tahap atau strategi dalam pelaksanaan permainan 
matematika. Menurut (Bell, 1981), tahap sebelum permainan, meliputi (a) guru harus memilih atau mengkreasikan permainan yang dapat mengembangkan kemampuan afektif dan kemampuan kognitif dalam matematika; (b) permainan yang digunakan harus disesuaikan dengan materi yang diajarkan sebelumnya sehingga tidak terjadi tumpang tindih antara materi matematika yang diajarkan sebelumnya dengan materi berikutnya; dan (c) guru harus benar-benar memahami aturan yang digunakan dalam permainan matematika. Hal tersebut perlu diperhatikan agar tujuan utama proses pembelajaran dapat tercapai. Selain itu, suasana pembelajaran jadi terarah dan menyenangkan. (Lyn, 2002) menambahkan bahwa permainan yang dikemas dalam pembelajaran matematika, dapat membuat siswa dapat berinteraksi dengan teman sebaya, dalam menyampaikan ide matematika yang dimilikinya. Siswa pun merasa lebih nyaman atau kuat menghadapi tantangan dalam pembelajaran matematika, misalnya siswa lebih berani menanyakan pertanyaan ketika tidak menemukan jawaban dari pertanyaan tersebut; siswa lebih berusaha untuk mencari jawaban dan mendiskusikan dengan orang lain, termasuk guru.

\section{METODE PENELITIAN}

Penelitian ini merupakan penelitian dan pengembangan (research and development). Bermain Pola merupakan hasil pengembangan permainan Building a House yang diperkenalkan Byron Barton dan A House for Hermit Crab yang diperkenalkan oleh Eric Carle (Husein, 2006). Permainan ini dikembangkan dalam permainan matematika agar siswa mampu mengidentifikasi sifat-sifat bangun datar serta mampu membedakan bangun datar berdasarkan sifat-sifatnya.

Pembuatan media permainan yang dikembangkan tersebut ditinjau dari berbagai aspek, yaitu pendefinisian, perancangan, bahasa, kesesuaian dengan indikator pembelajaran serta pemilihan gambar yang tepat. Setelah membuat media permainan dengan mempertimbangkan format pembuatan media yang baik, selanjutnya peneliti merancang kembali permainan tersebut dengan memperhatikan format karakteristik permainan yang ditinjau dari aturannya. Format karakteristik dari permainan yang dilihat pada aturannya, ditinjau dari aspek pendahuluan, inti serta akhir permainan.

Desain Bermain Pola diawali dengan melakukan pemilihan media dan perangkat pembelajaran. Permainan "Bermain Pola" dilengkapi dengan aturan permainannya serta perangkat pembelajaran berupa RPP, LKS, tes kemampuan 
spasial, lembar observasi aktivitas siswa, lembar pengamatan kemampuan guru dalam mengelola pembelajaran, dan angket respons siswa terhadap permainan tersebut. Sedangkan alat bantu pembelajaran yang diperlukan adalah pola-pola bangun datar, stopwatch dan peluit. Permainan ini diuji pada kelompok kecil dan kelompok besar di SDK Kumba 1, dengan memperhitungkan rata-rata skor kemampuan guru mengelola pembelajaran, respons siswa terhadap bermain pola, dan efektivitas bermain pola terhadap kemampuan spasial.

Data kemampuan spasial pada penelitian ini dikumpulkan menggunakan tes uraian, yang terdiri dari 1 soal kategori mudah, 1 soal kategori sedang dan 1 soal kategori sulit. Efektivitas permainan ini diuji dengan menggunakan one sample t-test, dengan menggunakan kriteria ketuntasan minimal sebesar 65 .

\section{HASIL PENELITIAN DAN PEMBAHASAN}

Permainan "Bermain dengan Pola" dikembangkan dengan beradaptasi pada permainan "Membuat Rumahku". Buku yang digunakan dalam membuat permainan "Membuat Rumahku" ini adalah Building a House yang diperkenalkan Byron Barton dan A House for Hermit Crab yang diperkenalkan oleh Eric Carle (Husein, 2006). Permainan "Membuat Rumahku" memberi kesempatan pada anak untuk meningkatkan kemampuan motorik halus, kemampuan menghitung dan belajar mengenai bentuk dan warna. Pada permainan ini, anak diminta memotong papan menjadi bentuk-bentuk segi empat dan segitiga; buat contoh rumah untuk ditunjukkan pada anak-anak; minta anak-anak mengamplas/ menghaluskan potongan-potongan kayu tersebut; rekatkan dinding rumah dan atapnya; tambahkan selotip kertas untuk pintu dan jendelanya; Cat atap rumahnya dan biarkan kering; cat dinding rumahnya lalu biarkan kering; boleh tambahkan nomor rumah. Permainan "Bermain dengan Pola" dikembangkan dari permainan ini yang dimodifikasi pada media dan aturan permainannya. Permainan "Bermain dengan Pola" berfungsi untuk meningkatkan kemampuan siswa dalam mengidentifikasi sifat-sifat bangun datar. Perangkat permainan ini berupa berbagai macam model bangun datar, stopwatch, dan peluit. Model bangun datar yang digunakan dalam permainan ini memiliki warna yang beragam. Permainan ini dilakukan selama 4 kali pertemuan di SDK Kumba 1. Siswa yang terlibat sebanyak 25 orang yang dibagi ke dalam 5 kelompok siswa.

Pada permainan ini, guru bertindak sebagai wasit dan pencatat skor, dengan tugas memberi tanda permainan dimulai dan berakhir; menentukan 
pemenang dalam permainan dan memberikan reward pada pemenang; mencatat skor pemain; menjatuhkan hukuman kepada kelompok yang melakukan pelanggaran serta guru memberi penilaian pada setiap permainan. Penilaian yang diberikan berupa Poin 10 jika kelompok tidak menyisakan satu bangun datar dan Poin 10 - n jika kelompok menyisakan $\mathrm{n}$ bangun datar.

Salah satu bentuk permainan yang dilakukan oleh kelompok siswa dalam satu pertemuan, menggunakan 2 kategori permainan. Permainan pertama yang dilakukan adalah merangkai bangun datar trapesium dari polapola bangun datar yang telah disediakan, tanpa menyisakan satu pun pola-pola bangun datar yang tersedia.
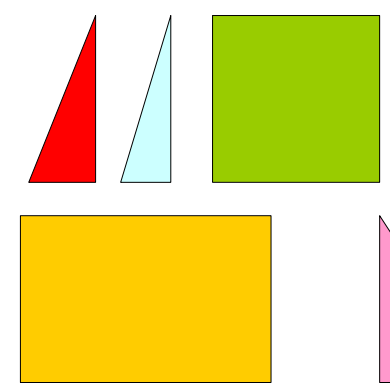
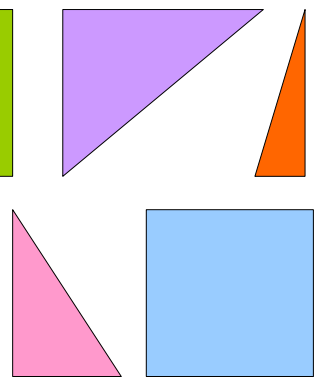
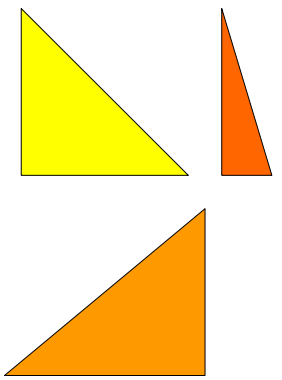

Gambar 3. Model-model Bangun Datar pada Permainan Pertama

Langkah pertama yang dilakukan pada permainan pertama adalah kelompok siswa mengumpulkan model bangun datar yang bentuknya serupa berupa segi empat dan segitiga. Kelompok siswa mengabaikan warna model bangun datar yang tersedia. Selanjutnya terjadi diskusi antara siswa mengenai kombinasi bangun datar yang harus mereka rangkai untuk membentuk model bangun datar trapesium. Sesuai dengan alokasi waktu permainan pertama, wasit membunyikan peluit sebanyak dua kali, sekaligus sebagai tanda pemain tidak boleh melakukan apa pun. Hasil rangkaian yang dibuat mahasiswa sangat bervariasi dengan jumlah model trapesium yang terbentuk juga beragam. Pada permainan pertama tidak satu pun kelompok yang menyisakan model bangun datar, sehingga semua kelompok mendapatkan poin 10. Hal ini terjadi karena model-model bangun datar yang tersedia pada permainan ini memiliki jumlah sangat sedikit.

Permainan kedua yang dilakukan kelompok siswa adalah membuat bangun datar layang-layang dari pola-pola bangun datar yang telah disediakan, tanpa menyisakan satu pun pola-pola bangun datar yang tersedia. 


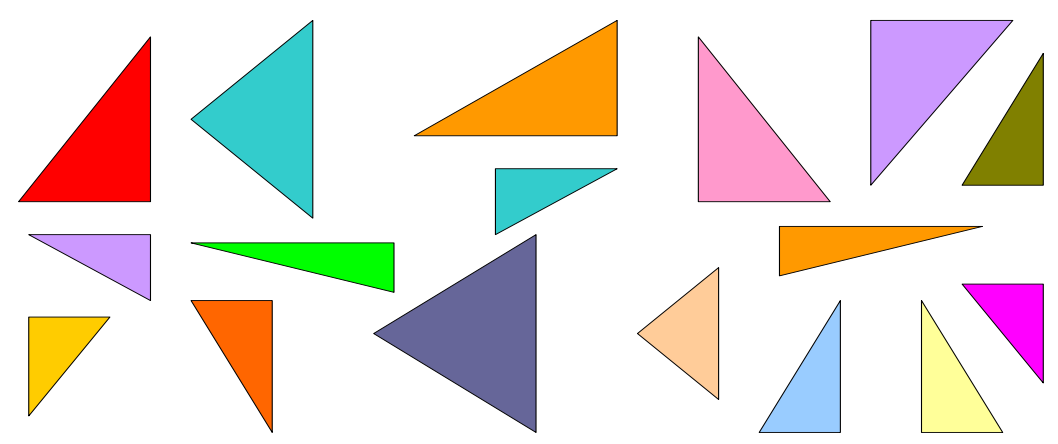

Gambar 4. Model-model Bangun Datar pada Permainan Kedua

Saat memainkan permainan ini, ada dua bentuk aktivitas yang dilakukan oleh kelompok-kelompok siswa. Bentuk aktivitas pertama adalah kelompok siswa memisahkan model bangun datar berdasarkan warnanya. Setelah dilakukan proses pemisahan berdasarkan warna, kelompok siswa tersebut memisahkan model bangun datar berdasarkan bentuknya, yaitu segitiga sama sisi, segitiga sama kaki dan segitiga siku-siku. Lalu kelompok siswa merangkai model-model bangun datar yang telah dipisahkan, berdasarkan bentuk, panjang sisi dan luas model bangun datar yang tersedia, sehingga menghasilkan model bangun datar layang-layang. Bentuk aktivitas kedua yang dilakukan kelompok siswa adalah memisahkan model bangun datar berdasarkan bentuknya, yaitu segitiga sama sisi, segitiga sama kaki dan segitiga siku-siku, tanpa membedakan warna dari model bangun datar tersebut. Kemudian kelompok siswa tersebut langsung membuat rangkaian dengan mencocokkan panjang sisi dari model-model bangun datar tersebut terlebih dahulu. Ada pula yang melakukan pemasangan dengan mencocokkan luas model-model bangun datar terlebih dahulu. Pada akhir permainan, kelompok siswa memberikan hasil rangkaian yang bervariasi. Ada kelompok yang mampu merangkai model-model bangun datar tersebut menjadi layang-layang , tanpa menyisakan satu pun bangun datar dalam permainan tersebut. Ada pula kelompok yang belum mampu merangkai semua model-model bangun datar yang tersedia menjadi layang-layang, sehingga menyisakan beberapa bangun datar pada akhir permainan.

Setelah dilakukan pertemuan sebanyak 4 kali, efektivitas Bermain Pola diuji menggunakan One Sample t test. Dari hasil analisis menggunakan SPSS 17 diperoleh $t_{\text {hitung }}=4.753$. Jika dikaitkan dengan kriteria pengujian, $t_{\text {hitung }}>t_{\text {tabel }}=$ 1,711, maka $\mathrm{H}_{0}$ ditolak. Maka dapat disimpulkan bahwa rata-rata kemampuan spasial siswa SDK Kumba 1 setelah menggunakan media permainan matematika berbasis karakter lebih besar dari 65 atau Penggunaan media 
permainan matematika berbasis karakter efektif terhadap kemampuan spasial siswa SDK Kumba 1.

Saat permainan "Bermain Pola" dilakukan di SDK Kumba 1, rata-rata skor kemampuan guru mengelola pembelajaran berada pada kriteria cukup baik. Berdasarkan analisis data kemampuan guru mengelola pembelajaran maka dapat disimpulkan bahwa guru memiliki kemampuan yang baik dalam menfasilitasi siswa dalam menggunakan media permainan berbasis karakter yang telah dirancang. Namun ketika proses pembelajaran berlangsung, guru menemukan banyak kendala, antara lain siswa belum terbiasa dengan permainan yang memiliki aturan. Permainan "Bermain Pola" merupakan hal baru buat mereka. Alat-alat yang digunakan dalam permainan pun adalah sesuatu yang baru buat mereka. Mereka hanya terbiasa dengan menggunakan model bangun datar yang bentuknya serupa. Kesulitan lain yang dialami oleh guru adalah ketika menyampaikan aturan permainan. Siswa harus dituntun secara penuh untuk mengikuti aturan permainan. Namun lambat laun, siswa bisa mengikuti permainan dengan cukup baik. Hal ini karena besarnya antusias siswa terhadap hal yang baru dan menarik. Hal ini terlihat jelas dari kemampuan guru membuat pembelajaran lebih asyik. Dari awal sampai akhir pembelajaran, ada perubahan positif dari segi melaksanakan tugas dalam permainan, berpartisipasi aktif, saling mendorong antar siswa. Tampak pula dalam proses pembelajaran siswa menghargai hasil pengundian urutan yang memulai permainan; adanya interaksi yang baik antara siswa dan guru juga sumber belajar, yang ditunjukkan oleh kefasihan siswa menggunakan media dan alatnya.

Saat permainan ditemukan juga aktivitas siswa mengelompokkan diri dengan kelompoknya. Para siswa fokus untuk menyelesaikan permainan tersebut. Pola-pola bangun datar diatur sedemikian rupa agar membentuk bangun datar sesuai dengan petunjuk permainan. Aktivitas siswa yang paling mencolok adalah usaha untuk tidak menyisakan pola-pola bangun datar yang tersedia. Aktivitas ini sangat relevan dengan tahap menalar atau mengasosiasi. Hal ini sejalan dengan analisis yang dilakukan Kurnila (2013) terhadap standar proses K13, yaitu pada tahap ini siswa harus melakukan kegiatan yang kreatif, yaitu menentukan strategi yang tepat dengan mengolah dan menyatukan informasi pada tahap mengamati, bertanya dan mengumpulkan informasi. Sehingga bisa ditemukan sebuah pola untuk menyelesaikan masalah yang diberikan saat proses pembelajaran maupun persoalan-persoalan serupa. Pada saat pembelajaran berlangsung perilaku yang tidak relevan dengan kegiatan 
pembelajaran seperti percakapan di luar pembelajaran, berjalan-jalan di luar kelompoknya, serta mengerjakan sesuatu di luar topik pembelajaran sangat jarang terjadi. Siswa menyukai pembelajaran yang dikemas dalam bentuk permainan, media sebagai pendukung permainan, serta gambar, tulisan, warna yang tertera pada media sangat menarik perhatian siswa.

\section{SIMPULAN}

"Bermain Pola" merupakan salah satu alternatif permainan dalam pembelajaran matematika. Aktivitas ini bisa dilakukan dengan media dan cara yang sangat praktis. "Bermain Pola" juga dikemas dalam bentuk permainan yang menggunakan aturan, sehingga proses pembelajaran lebih terarah dan berdampak baik pada peningkatan kemampuan spasial siswa. "Bermain Pola" membantu siswa dalam mengidentifikasi sifat-sifat bangun datar. Siswa memiliki kemampuan mengidentifikasi bangun datar yang memiliki sifat ukuran sama, mengidentifikasi bangun datar yang memiliki sifat sama meskipun ukuran atau warna berbeda, serta menggabungkan beberapa bangun datar menjadi bangun datar dengan bentuk yang sama atau bentuk yang baru.

\section{DAFTAR PUSTAKA}

Bayram, H. Y. (2009). On the development and measurment of spatial ability. Internasional Electronic Journal of Elementary Education, 9(1), 83-96. Retrieved from https:/ / eric.ed.gov/?id=EJ1052049

Bell, F. H. (1981). Teaching and learning mathematics (in secondary schools). Iowa: Wm. C. Brown Company.

Derek, H. (2007). Teaching primary mathematics. London: Sage Publication.

Dickyandi, N. (2016). Metode mengajar ala Tiongkok dan Jepang. Yogyakarta: DIVA Press.

Husein, T. K. (2006). Permainan kreatif berbasis topik. Jakarta: Erlangga.

Kurniawan, Y., Jelatu, S., Adi, N. P., \& Kurnila, V. S. (2018). An android-based application to improve the ability to draw and interpret fbd. 01(01), 172-187.

Kurnila, V. S. (2013). Kontribusi standar proses pada kurikulum 2013 guna meningkatkan kemampuan algoritmik siswa. Jurnal Pendidikan Dan Kebudayaan Missio, 10(1), 53-58.

Lyn, E. D. (2002). International research in mathematics education. London: Lawrence Erlbaurm Associates.

Nugroho Prasetya, A., \& Yohanes, K. (2018). Meningkatkan higher order thinking skill dan sikap terbuka melalui media pembelajaran android. Journal of Komodo Science Education, 01(01), 79-94.

Peker, M. (2008). Pre-service elementary school teachers' learning styles and 
attitudes towards mathematics. Eurasia Journal of Mathematics, Science $\mathcal{E}$ Technology Education, 4(1), 21-26.

Ramda, A. H., Kurnila, V. S., \& Jundu, R. (2018). Implementasi kurikulum 2013 pada standar isi buku teks matematika kelas VIII. Jurnal Eksakta Pendidikan (Jep), 2(2), 162. https:/ / doi.org/10.24036/jep/vol2-iss2/231

Seifert, K.L. \& Hoffnung, R. J. (1987). Child and adolescent development. Boston: Houghton Mifflin Company.

Suwarma, D. M. (2009). Suatu alternatif pembelajaran kemampuan berpikir kritis matematika. Jakarta: Cakrawala Maha Karya.

Tosto, M. G., Hanscombe, K. B., Haworth, C. M. A., Davis, O. S. P., Petrill, S. A., Dale, P. S., ... Kovas, Y. (2014). Why do spatial abilities predict mathematical performance? Maria. Developmental scince, 17(3), 462-170. https:// doi.org/10.1053/j.jvca.2010.06.032

Wahyudin. (2015). Penelitian pendidikan matematika. Bandung: Refika Aditama. 